\title{
The Cognition of Palliative Nursing among Nursing Students at Different Levels after Clinical Practice: A Survey Study
}

\author{
Zhenjun Niu, Hong Zhou* \\ Department of Medicine, Yangtze University, Jingzhou, China \\ Email: ${ }^{\star} 1059634547 @ q q . c o m$
}

How to cite this paper: Niu, Z.J. and Zhou, H. (2018) The Cognition of Palliative Nursing among Nursing Students at Different Levels after Clinical Practice: A Survey Study. Yangtze Medicine, 2, 73-81. https://doi.org/10.4236/ym.2018.22008

Received: March 12, 2018

Accepted: June 8, 2018

Published: June 11, 2018

Copyright $\odot 2018$ by authors and Scientific Research Publishing Inc. This work is licensed under the Creative Commons Attribution International License (CC BY 4.0).

http://creativecommons.org/licenses/by/4.0/

\section{c) (i) Open Access}

\begin{abstract}
Objective: To understand the status of cognition of palliative nursing among nursing students at different levels, and provide a basis for palliative nursing education. Methods. 268 nursing students from different levels were investigated by the palliative nursing cognition questionnaire and Chinese version of palliative nursing knowledge questionnaire (PCQN). Results. Students with clinical probation and from non single parent family normally have higher knowledge scores than those without clinical probation and from single parent families $(p<0.05)$; statistical differences were observed in seven aspects of palliative care $(\mathrm{p}<0.05)$; the undergraduates have higher scores, compared to students of junior college and secondary school in dimension two and total score $(\mathrm{p}<0.05)$; the factors include the experience of probation and the grade getting from internship hospital. Conclusion: It's important for schools and hospitals to strengthen the theory teaching of palliative nursing, combine clinical practice with the theory education closely and improve the teaching level of teachers, which are aimed to promote the rapid development of palliative care.
\end{abstract}

\section{Keywords}

Nursing Students, Palliative Nursing, Cognition

\section{Introduction}

The incidence of chronic diseases has increased in the recent years when the change of disease spectrum appears. Therefore, chronic patients and their caregivers' quality of life have become an increasing concern. World Health Organization (WHO) proposed that adults is suffering from cancer, Alzheimer's dis${ }^{\star}$ Corresponding author. 
ease, cardiovascular disease, chronic obstructive pulmonary disease, diabetes, AIDS, liver cirrhosis, renal failure, multiple sclerosis, Parkinson syndrome, rheumatoid arthritis, drug resistant tuberculosis; meanwhile, children also suffer from cancer, cardiovascular disease, meningitis, cirrhosis, kidney disease, congenital malformation, blood and immune dysfunction, AIDS, neurological disorders and neonatal abnormalities. Therefore, these two age groups both need palliative care mode to improve the quality of their own life [1] [2]. Nursing students are the main force of palliative care personnels in the future. What knowledge and attitude of palliative care they will receive directly affects the future development and implementation of palliative care. The purpose of this study is to understand the status quo of palliative care knowledge acquisition for different levels of nursing students, which can help provide the basis for schools and hospitals to carry out publicity and education of palliative care knowledge, promoting the development of palliative nursing career.

\section{Objects}

268 nursing students, including 32 nursing students in polytechnic school, 126 junior college students and 110 undergraduates, were selected from 4 teaching hospitals by using cluster random sampling method, containing 16 boys and 252 girls. Their average age was $(22.13 \pm 3.51)$ years, all of these eligible students were informed in advance.

\section{Methods}

\subsection{Study Design}

We conducted a cross-sectional descriptive survey of the cognition of palliative care of different levels' nursing students during the period from September 2016 to May 2017. The study is approved by the university and hospital ethics Department.

\subsection{Investigative Tools}

The questionnaire (available from the authors) is divided into three parts: 1) the basic information: age, sex, degree, ethnic groups, single child, birthplace and so on. 2) Palliative care cognition questionnaire is designed on the basis of reference literature [3]. It has 21 items, including whether and where to know palliative care, whether or not to think about how to spend the end of life. 3) The Chinese version of the palliative nursing knowledge questionnaire (PCQN) [3], with a total of 20 items, is divided into three dimensions. They are palliative care philosophy and principles (4 items), control of pain and other symptoms (13 items), and psychosocial support ( 3 items). Each item is 1 point.

\subsection{Data Collection Procedure}

Questionnaires were issued at the last one week of the internship, because nursing students have had a certain accumulation of knowledge and practice at the 
end of the internship period. A cluster sample of 280 nursing students are surveyed, 268 are reclaimed and the effective recovery rate is $95.714 \%$.

\subsection{Statistical Data Analyses}

Data analyses are performed by using WPS excel software. Appropriate descriptive statistics, including frequency (percentage) and mean (standard deviation, $\mathrm{SD}$ ) are used to present the background characteristics, including gender, student source, one-child, single-parent family, probation. To compare any difference in degree and cognitive abilities on palliative nursing among recruits, Chi square test and t-test are conducted to examine the results.

\section{Results}

1) Comparison of the scores of different demographic characteristics and palliative nursing knowledge after nursing clinical practice.

There is no significant difference in the scores of palliative care knowledge among different gender, student sources and one-child after internship ( $\mathrm{p}>$ $0.05)$. Significant difference was observed in probationary experience and single parent family $(\mathrm{p}<0.05)$ (Table 1$)$.

2) Comparison of the cognition of palliative nursing after nursing students at different levels.

The cognition of palliative nursing at different levels have statistical significance in cognition of $1,4,6,8,9,10$ and 11 items $(\mathrm{p}<0.05)$. The cognitive level of undergraduate nursing students is higher than that of college nursing students, and the cognitive level of college nursing students is significantly better than that of secondary school nursing students. There is no significant difference in cognitive differences between the 2, 3, 5, 7 and 12 questions at different levels ( $\mathrm{p}>$ 0.05) (Table 2).

3) Comparison of the scores of different dimensions of palliative nursing

Table 1. Comparison of the scores of different demographics and palliative nursing knowledge $(\bar{x} \pm S)$.

\begin{tabular}{cccccc}
\hline Item & Category & Number $(\mathrm{n})$ & $\bar{x} \pm \mathrm{S}$ & $\mathrm{t} / \mathrm{U}$ & $\mathrm{P}$ \\
\hline \multirow{2}{*}{ Gender } & male & 16 & $31.1250 \pm 12.05271$ & & \\
& female & 252 & $34.1587 \pm 7.93212$ & -1.0140 & $>0.05$ \\
& City & 56 & $35.3214 \pm 9.37709$ & & \\
Student source & countryside & 212 & $33.6226 \pm 7.87576$ & & \\
& Yes & 104 & $34.8077 \pm 9.20579$ & & \\
One-child & No & 164 & $33.4512 \pm 7.51156$ & 1.2601 & $>0.05$ \\
Single-parent & Yes & 40 & $31.2000 \pm 9.07048$ & & \\
family & NO & 228 & $34.4649 \pm 7.98581$ & -2.1359 & $<0.05$ \\
Probation & Yes & 224 & $37.6818 \pm 8.75261$ & & \\
& No & 44 & $33.2500 \pm 7.93044$ & & $<0.05$ \\
\hline
\end{tabular}


Table 2. Comparison of the cognition of palliative nursing after nursing students at different levels (n, \%).

\begin{tabular}{|c|c|c|c|c|c|}
\hline \multirow[t]{2}{*}{ subject } & $\begin{array}{l}\text { Secondary school } \\
\text { students }(\mathrm{n}=32)\end{array}$ & $\begin{array}{l}\text { junior college student } \\
\qquad(\mathrm{n}=126)\end{array}$ & $\begin{array}{l}\text { Undergraduate } \\
\qquad(\mathrm{n}=110)\end{array}$ & \multirow[t]{2}{*}{$\chi^{2}$} & \multirow[t]{2}{*}{$\mathrm{P}$} \\
\hline & $\mathrm{N}(\%)$ & $\mathrm{N}(\%)$ & $\mathrm{N}(\%)$ & & \\
\hline 1) Know palliative care & $3(9.38)$ & $68(53.97)$ & $99(90.00)$ & 78.652 & 0.00 \\
\hline $\begin{array}{l}\text { 2) Think about how to spend a time before } \\
\text { the death }\end{array}$ & $6(18.75)$ & $27(1.05)$ & $36(32.72)$ & 4.852 & 0.09 \\
\hline $\begin{array}{l}\text { 3) Think about how to spend the last time } \\
\text { with a dying family }\end{array}$ & $8(25.00)$ & $18(14.29)$ & $16(14.55)$ & 2.396 & 0.30 \\
\hline $\begin{array}{l}\text { 4) Talk to a family or a friend about how to } \\
\text { face the topic of death }\end{array}$ & $1(3.10)$ & $22(17.46)$ & $28(25.45)$ & 8.402 & 0.01 \\
\hline $\begin{array}{l}\text { 5) Spend the dying time with a loved one or a } \\
\text { friend }\end{array}$ & $2(6.25)$ & $9(7.14)$ & $12(10.91)$ & 1.314 & 0.52 \\
\hline 6) Take part in nursing over deathbed patients & $5(15.63)$ & $30(23.81)$ & $44(40.00)$ & 10.760 & 0.00 \\
\hline $\begin{array}{l}\text { 7) Discuss how to face death with a deathbed } \\
\text { or family member }\end{array}$ & $0(0.00)$ & $5(3.97)$ & $7(6.36)$ & 2.491 & 0.29 \\
\hline $\begin{array}{l}\text { 8) Differentiation of palliative care and } \\
\text { hospice care }\end{array}$ & $0(0.00)$ & $8(6.35)$ & $26(23.64)$ & 21.124 & 0.00 \\
\hline $\begin{array}{l}\text { 9) The importance of palliative nursing } \\
\text { education }\end{array}$ & $13(40.63)$ & $56(44.44)$ & $90(81.82)$ & 39.264 & 0.00 \\
\hline $\begin{array}{l}\text { 10) Willing to know the knowledge of } \\
\text { palliative care }\end{array}$ & $26(81.25)$ & 99 (78.57) & $106(96.36)$ & 16.370 & 0.00 \\
\hline $\begin{array}{l}\text { 11) Palliative care is suitable for } \\
\text { patients with malignant tumors }\end{array}$ & $15(46.88)$ & $56(44.44)$ & $92(83.64)$ & 40.822 & 0.00 \\
\hline 12) Religious belief & $0(0.00)$ & $3(2.38)$ & $1(00.91)$ & 1.416 & 0.49 \\
\hline
\end{tabular}

knowledge after clinical practice at different levels.

The score of whole and dimension two of palliative nursing knowledge is statistically significant $(\mathrm{p}<0.05)$ after clinical practice at different levels. The total score of the Undergraduates' palliative nursing knowledge and the score of dimension 2 is higher than those of junior college students and secondary school students, and the difference is statistically significant $(\mathrm{p}<0.05)$. There is no statistical significance in the scores of 1 and 3 dimensions $(p>0.05)$ for the nursing knowledge questionnaire of the nursing students at different levels $(p>0.05)$ (Table 3).

4) Multiple stepwise retrospective analysis of the factors influencing the score of palliative nursing knowledge after clinical practice at different levels.

The factors are the nurses' experience in probation and internship hospital level (Table 4).

\section{Discussion}

Palliative care is the extension of high-quality clinical nursing service. Nursing students will be the backbone of future clinical nursing staffs. Their palliative nursing knowledge level will affect the future nursing practice behavior, and 
Table 3. Comparison of the scores of different dimensions of palliative nursing knowledge after nursing students at different levels $(\bar{x} \pm S)$.

\begin{tabular}{cccccc}
\hline & $\begin{array}{c}\text { Secondary } \\
\text { school } \\
\text { students } \\
(\mathrm{n}=32)\end{array}$ & $\begin{array}{c}\text { Junior college } \\
\text { student } \\
(\mathrm{n}=126)\end{array}$ & $\begin{array}{c}\text { Under-graduate } \\
(\mathrm{n}=110)\end{array}$ & $\mathrm{F}$ & $\mathrm{p}$ \\
\hline $\begin{array}{c}\text { Dimension 1: } \\
\text { philosophy and } \\
\text { principles }\end{array}$ & $7.88 \pm 2.83$ & $7.20 \pm 2.34$ & $7.96 \pm 2.93$ & 1.13 & 0.33 \\
$\begin{array}{c}\text { Dimension 2: control of } \\
\text { pain and symptoms }\end{array}$ & $22.50 \pm 5.03$ & $21.23 \pm 5.085$ & $25.36 \pm 6.88$ & 5.30 & 0.01 \\
$\begin{array}{c}\text { Dimension 3: } \\
\text { psycho-social and } \\
\text { spiritual support }\end{array}$ & $4.38 \pm 1.21$ & $4.42 \pm 1.25$ & $5.05 \pm 1.96$ & 1.93 & 0.15 \\
The total score & $34.75 \pm 7.56$ & $32.84 \pm 7.23$ & $38.36 \pm 1.05$ & 4.34 & 0.02 \\
\hline
\end{tabular}

Table 4. Multiple stepwise retrospective analysis of the factors influencing the score of palliative nursing knowledge after nursing students at different levels.

\begin{tabular}{ccccc}
\hline Selection factors & $\begin{array}{c}\text { regression } \\
\text { coefficient }\end{array}$ & $\begin{array}{c}\text { Standard regression } \\
\text { coefficient }\end{array}$ & $\mathrm{t}$ & $\mathrm{p}$ \\
\hline Probation experience & 2.03 & 0.21 & 2.23 & 0.03 \\
teaching hospital level & 1.52 & 0.21 & 2.06 & 0.04 \\
\hline
\end{tabular}

affect the quality of palliative care as well. Therefore, the education of palliative nursing among nursing students is strengthened to cultivate palliative nursing talents and guarantee the quality of palliative nursing.

\subsection{Cognitive on Palliative Nursing at Different Levels of Nursing Students}

\subsubsection{Scores of Palliative Nursing Knowledge among Nursing Students after Clinical Practice with Different Demographic Characteristics}

The results show that palliative care knowledge scores of nursing students and non single parent nursing students are better than those of non trainee and single parent nursing students $(\mathrm{p}<0.05)$. There is no significant difference in gender, birthplace, and only-child ( $p>0.05)$. The main reason is that, firstly, students can contact with palliative nursing care of patients during probation, and then understand the requirements of student knowledge and skills, to strengthen weak links of learning [4]; secondly, nursing students in single parent families have less family and social support because of the changes of family and their living environmental, which influences their mental health and learning outcomes. Therefore, the score of nursing students in non single parent families is better than that of them [5]. This suggests that educators in schools and hospitals should pay attention to nursing students in single parent families, so we should teach students in accordance with their aptitude to improve their learning enthusiasm; thirdly, nursing students in terms of gender, source of students, whether only children in a family have no significant difference, which may be 
related to Chinese traditional culture. Palliative care is not being talked about in daily life freely. Palliative nursing education is ignored in school.

Our research showed that it has statistically significant in the aspects of knowing palliative care, talking about palliative care with relatives or friends, involving the care, distinguishing the palliative care from hospice care, knowing palliative care's importance, being willing to understand, and palliative care being suitable for malignant patients $(\mathrm{p}<0.05)$. The cognitive level of undergraduate nursing students is higher than that of college nursing students, and the cognitive level of college nursing students is significantly better than that of secondary school nursing students. Because the undergraduates accept longer time and more extensive education, their understanding and cognitive level of palliative care is relatively higher. Thinking about how to spend the last time of life, how to accompany the dying relatives, having the experience, and discussing how to face death, religious belief differences have no significance ( $p>0.05)$. First of all, death education curriculum is rarely involved in primary and secondary schools, and attached to the psychology and ethics courses in the universities of China, so students have a fear of dying, and escape the topic; Secondly, students have a superficial understanding of the nature of religion, which is the main factor contributing to the indifference between the cognitions above. Therefore, the deathbed education should start from the basic education, bring into the school education, and set up the teaching goals at different levels finally.

\subsubsection{Score of Palliative Nursing Knowledge after Nursing Students at Different Levels}

From Table 3. The score of whole and dimension two of palliative nursing knowledge are statistically significant $(\mathrm{p}<0.05)$. The total score, pain and symptom control scores of undergraduates is higher than junior college and secondary school students $(\mathrm{p}<0.05)$; the scores of palliative care philosophy and principles, psychosocial and spiritual support show no significant difference ( $\mathrm{p}>$ $0.05)$. The reasons may be that undergraduate education is given more focus, and the well-educated students have the more willingness of new nursing ideas [6]. Secondly the school and hospital attach great importance to the management of pain. The palliative care and psychological nursing is a new discipline in China, and little involved in textbooks. Because there is no difference between students of different degrees in dimension 1 and 3, so it is urgent to strengthen College palliative nursing education.

\subsection{Multiple Factors Analysis on the Score of Nursing Students' Knowledge of Palliative Care}

This study shows that the main influence factors are whether having probation and the grade of the internship hospitals. The reason is that nursing students can better understand the relationship between palliative care theoretical knowledge and clinical practice through probation and further study [7]. The teaching levels of clinical nursing teachers are different. Fang found that the comprehensive 
education quality and ability of clinic teachers in the third grade hospital were significantly better than the second. The excellent rate is less than $50 \%$, which cannot meet the requirements of students [8]. Palliative care is widely applied in economically developed areas and high level hospitals in China. Due to the limited conditions in underdeveloped areas and low-level hospitals, nursing staff's have less palliative care knowledge [6] [9].

\subsection{Counter Measures}

\subsubsection{Strengthen the Theory Teaching of Palliative Nursing}

Education must be done first before the development of any subject. Palliative care has been incorporated into medical education in some countries such as the United States, Canada and the United Kingdom. The European palliative care association established a medical undergraduate course in palliative care in 2007 [10] [11]. In 2016, American Association of Colleges of Nursing renewed and suggested that it is one of the nurses' abilities to provide the palliative care for patients with serious diseases and their families [2]. China Taiwan began palliative care education in 1993, but the development of palliative care in the mainland is unsatisfactory. There are no normal palliative care courses and unified standard, so nursing students can not accept systematic theoretical study [12]. In the view of the above reasons, we should learn foreign palliative education ideas and patterns, and explore our own system of palliative nursing courses. Taking palliative care as an optional or required course, adding its teaching hours to 18 30 hours [13], and enriching teaching forms, to help nursing students learn it systematically.

\subsubsection{Close Combination of Clinical Practice}

Palliative care is a discipline that focuses on clinical practice. In 2016, the American palliative care association claimed that nursing students need to learn 17 skills related to hospice care during their studies, and there is a special practice system [14]. Universities in China rarely cooperate with palliative medical institutions, and lack corresponding educational resources. There is no practical system suitable for palliative care and corresponding plan in clinical practice, and then nursing students have little knowledge of this field after entering the clinical practice [12] [13]. Therefore, colleges and universities need to strengthen communication and cooperation, optimize teaching resources, and achieve sharing and complementation. In the process of teaching, we should strengthen theory and practice, and increase the time of clinical practice. After 2-hour of theoretical teaching, we arrange 4 - 6 hour clinical probation, which help students give patients bedside care, to experience patients' needs for palliative care, and encourage these nursing students to be a volunteer after class. Hospitals should formulate relevant internship programs to make the palliative care education throughout the whole probation of nursing students. According to different departments, palliative nursing training may be targeted to carry out to consolidate the theoretical knowledge of nursing students, improving their cog- 
nition and palliative nursing skills from multiple angles.

\subsubsection{Improve the Teaching Level of Teachers}

Palliative care in China is a new field which is developing. It lacks professional certification and knowledge training, and a professional nursing team as well. Teachers' abilities of theory and practice have a considerable gap with the international level, which directly influence the quality of teaching [6] [7]. Therefore, the school should optimize the allocation of teachers resources, strengthen cooperation with professional institutions of palliative care, such as hospitals, communities and funeral homes. At the same time, engaging experts with rich experience in palliative medicine and nursing, and training teachers in multiple ways. Teachers should participate in clinical practice and various academic exchanges regularly, go abroad for further study to enhance their comprehensive teaching ability.

In summary, there are differences between different levels of nursing students in palliative care knowledge. Schools and hospitals should be targeted at carrying out the education of palliative care knowledge to improve nursing students' knowledge level of palliative care and help them better implement palliative care in the clinic, promoting the rapid development of palliative care.

\section{Limitations}

Our study only investigated the status of cognition and knowledge of palliative care of nursing students at different levels after their internship, and analyzed the related factors. However, we did not have an in-depth study of the specific measures for the popularization and education of palliative knowledge. Further practical research on its popularization may be done on the basis of related factors affecting students' cognition and knowledge of palliative care.

\section{References}

[1] Zhang, H.Z., Shang, L.Y. and Huang, Z. (2016) Practice of Palliative Care for Hospitalized Patients with Advanced Cancer. Chinese Nursing Management, 16, 407-409.

[2] Lu, Y.H. (2017) The Present Situation and Development Direction of Hospice Care in China. Chinese Journal of Nursing, 52, 407-410.

[3] Worldwide Palliative Care Alliance (2014) Global Atlas of Palliative Care at the End of Life. Worldwide Palliative Care Alliance, London, 10.

[4] Zhang, L.J., LI, Y.Q., Huang, S.M., et al. (2012) Study on Work Process-Oriented Integrated Clinical Probation Mode for Higher Vocational Nursing Students. Journal of Nursing, 19, 26-28.

[5] Xie, J. (2010) The Personality Characteristic and Relevant Factors of the Single-Parent Nursing Students in a Vocational School. Xin Jiang Medical University.

[6] Zou, M. (2007) Investigation and Analysis on the Status Quo of Nurses' Palliative Nursing Knowledge and Attitude in Shanghai. The Second Military Medical University.

[7] Zhang, F.Q., Chen, H.Y., Ding, J., et al. (2016) The Influence of "Three Early Type 
Probation" Model on Self-Guidance Ability of Nursing Students in Higher Vocational Colleges. Journal of Nursing Education, 31, 824-826.

[8] Fang, X.X., Liu, F., Xu, H.M., et al. (2009) Investigation and Countermeasures of Nursing Clinical Teaching in Different Levels of Medical Colleges and Universities in Higher Medical Colleges. China Higher Medical Education, 3, 90-92.

[9] Chen, X.M. (2011) Investigation on the Status Quo of Community Nurses' Palliative Care in Changchun. Jilin University.

[10] European Association for Palliative Care (2015) Core Competencies in Palliative care: An EAPC White Paper on Palliative Care Education-Part 1. http://www.ejpc.eu.com

[11] Zhang, Y.X., Wu, J.F., Fan, Y.X., et al. (2013) Survey on Knowledge of Palliative Care among Nurses Working in Geriatric Department. Journal of Nursing, 28, 44-46.

[12] Zou, M. (2015) Investigation and Analysis on Status Quo of Grasping Knowledge about Palliative Nursing of Nurses in Shanghai. Chinese Journal of Practical Nursing, 31, 1386-1390.

[13] Ye, H.D. and Yin, H.Y. (2014) The Status and Enlightenment of the Undergraduate Palliative Nursing Courses in the United States and Australia. Nursing Journal of Chinese People's Liberation Army, 31, 65-67.

[14] Ferrell, B., Malloy, P., Mazanec, P., et al. (2016) CARES: AACN's New Competencies and Recommendations for Educating Undergraduate Nursing Students to Improve Palliative Care. Journal of Professional Nursing, 32, 327-333.

https://doi.org/10.1016/j.profnurs.2016.07.002 